This item was submitted to Loughborough's Research Repository by the author.

Items in Figshare are protected by copyright, with all rights reserved, unless otherwise indicated.

\title{
Exploring athletes' perceptions of coach stress in elite sport environments
}

PLEASE CITE THE PUBLISHED VERSION

https://doi.org/10.1080/02640414.2016.1154979

PUBLISHER

(C) Taylor \& Francis

VERSION

AM (Accepted Manuscript)

\section{PUBLISHER STATEMENT}

This work is made available according to the conditions of the Creative Commons Attribution-NonCommercialNoDerivatives 4.0 International (CC BY-NC-ND 4.0) licence. Full details of this licence are available at: https://creativecommons.org/licenses/by-nc-nd/4.0/

\section{LICENCE}

CC BY-NC-ND 4.0

\section{REPOSITORY RECORD}

Thelwell, Richard C., Christopher R.D. Wagstaff, Adam Rayner, Michael Chapman, and Jamie Barker. 2019. "Exploring Athletes' Perceptions of Coach Stress in Elite Sport Environments". figshare. https://hdl.handle.net/2134/28215. 
1 Thelwell, R.C., Wagstaff, C.R.D., Rayner, A., Chapman, M., \& Barker, J. (in press).

2 Exploring athletes' perceptions of coach stress in elite sport environments. Journal of Sports

3 Sciences.

4

5 Paper accepted $-11^{\text {th }}$ February, 2016 
Abstract

2 The present study aimed to extend research that has focused on the identification of

3 stressors associated with coaching practice by systematically evaluating how such

4 stressors effect athletes, and more broadly, the coach-athlete relationship. A total of

513 professional and national level athletes were interviewed to address the three study

6 aims: how they detect when a coach is encountering stressors; how coach experiences

7 of stress effects them as an athlete; and, how effective the coach is when experiencing

8 stress. Following content analysis, the data suggested athletes were able to detect

9 when a coach was experiencing stress and this was typically via a variety of verbal

10 and behavioural cues. Despite some positive effects of the coach experiencing stress,

11 the majority were negative and varied across a range of personal influences on the

12 athlete, and effects on the general coaching environment. It was also the broad view

13 of the athletes that coaches were less effective when stressed, and this was reflected in

14 performance expectations, perceptions of competence, and lack of awareness. The

15 findings are discussed in relation to the existing theory and with reference to their

16 implications for applied practice, future research, and development of the coach-

17 athlete relationship.

18 Key words: appraisals, interviews, qualitative analysis, strain, transaction 


\section{Exploring athletes' perceptions of coach stress in elite sport environments}

The quest to understand stress experiences in a range of occupational performance domains involving high levels of human interaction has been a main focus of research attention in recent years (e.g., law enforcement: Kinman \& Jones, 2008; nursing and mental health workers: Bennett, Lowe, Matthews, Dourali, \& Tattersall, 2001; management: Kerr, McHugh, \& McCrory, 2009). With literature suggesting stress experiences to exist in wide-ranging professions, a further environment that warrants inclusion is that of sport, where athletes (Hanton, Fletcher, \& Coughlan, 2005), coaches (Knight, Reade, Selzler, \& Rodgers, 2013), parents (Harwood \& Knight, 2009), and sport psychologists (Fletcher, Rumbold, Tester, \& Coombes, 2011), experience such issues.

Before proceeding, it is important to define the key variable of focus. We define stress as, "an ongoing process that involves individuals transacting with their environments, making appraisals of the situations they find themselves in, and endeavouring to cope with any issues that may arise" (Fletcher, Hanton, \& Mellalieu, 2006, p. 329). Accordingly, we use the term stress to represent a process incorporating stressors, demands, strains, appraisals, and coping responses, and not specific components of the transaction between the person and the environment, such as stressors (i.e., environmental demands encountered by an individual) or strain (i.e., an individual's response to stressors).

Much of the stress research in sport has been, and continues to be, focused towards elite athletes' experiences (e.g., Kristiansen \& Roberts, 2010), although more recently, attention has expanded to include the stress experiences of elite coaches who, when operating at the highest level, do so within the constraints of a dynamic, complex and pressurised environment. It is also reasonable to argue that their 
1 continued employment is likely to be influenced by the immediate desire for

2 successful performance outcomes (Fletcher \& Scott, 2010). When scrutinising their

3 role further, coaches influence a myriad of performance components that include

4 issues related to team and squad selection, athlete well-being and performance, the

5 organisation, and administrative duties (including role and contract negotiations,

6 human resource issues); all of which require attention whilst the coach is trying to

7 ensure that their own performance state is optimised (Gould, Greenleaf, Guinan, \&

8 Chung, 2002). With these roles in mind, one could suggest that coaching in elite sport

9 is not only highly demanding, but worthy of stress-focused research given the

10 possible general health and well-being concerns associated with the

11 professionalisation of sport (see Fletcher \& Wagstaff, 2009).

Turning to research relating to stress in sports coaches, recent studies have

13 employed qualitative methods to explore the stressors experienced and associated

14 coping responses and outcomes. For example, in a study of collegiate coaches, Frey

15 (2007) reported stressors to be associated with interpersonal and personal factors,

16 influences of other people, task-related factors, and factors that would lead to them

17 relinquishing their position. As such, many of the stressors were perceived to have a

18 negative effect on coaching performance due to the debilitative influence on

19 emotional control, concentration and decision making. Further insights to the study of

20 coach stress have resulted from work conducted by Thelwell, Weston, Greenlees, and

21 Hutchings (2008) and Olusoga, Butt, Hays, and Maynard, (2009) who reported

22 similar stressors to be experienced by UK elite level coaches across various sports.

23 Such stressors include those emanating from athlete performance (e.g., athlete

24 coachability, training performance), the performance of the coach (e.g., training, 
1 competition preparation) and the organisation in which the coach operates (e.g.,

2 training and competition environment, finances).

Despite the growing body of research highlighting the importance of

4 examining the stress experiences of coaches, the psychosocial effects of such

5 experiences, both to the coach themselves, and their athletes, are relatively unknown.

6 For example, although the coach-athlete relationship is reported as being critical,

7 questions remain as to how coach stress, and the resultant strain, may influence the

8 relationship and subsequent aspects relating to athlete satisfaction, performance and

9 general well-being (Poczwardowski, Barott, \& Jowett, 2006). To elaborate, research

10 has shown that stressors experienced by athletes can emanate from the coach (e.g.,

11 Gould, Greenleaf, Guinan, Dieffenbach, \& McCann, 2001), with athletes

12 experiencing wide-ranging psychological effects following poor coaching (Gearity \&

13 Murray, 2011). Both Holt and Hogg (2002) and Noblet and Gifford (2002) in their

14 respective football studies cited issues relating to poor communication (e.g., lack of

15 feedback) and poor relationships with coaches as significant contributors to the stress

16 experienced by athletes. Related to this, athletes have reported numerous

17 organisational stressors to stem from leadership and/or coaching issues that result in a

18 wide range of emotions, attitudes and behaviours (Fletcher, Hanton, \& Wagstaff,

19 2012), and that expectations driven by coaches' perceptions influence the level of

20 stress experienced (Thelwell, Weston, \& Greenlees, 2007).

21 Not only have athletes reported their stress to be influenced by the behaviour

22 and actions of coaches, but coaches themselves also acknowledge how their negative

23 reactions to stress can affect athletes. Referring back to the work by Frey (2007) with

24 collegiate coaches, nearly half of the coaches interviewed perceived their stress to

25 negatively influence their athletes within performance (e.g., not enabling the athletes 
1 to relax) and general day-to-day environments (e.g., athletes finding coaches unapproachable). In turn, it was reported that this often resulted in unnecessary worry

3 and anxiety being experienced by athletes. Furthermore, Olusoga, Butt, Maynard, and

4 Hays (2010) in their study of stress and coping in world class coaches revealed that

5 the perceived effects of stress on coaches related not only to "negative effects on the

6 coach' (e.g., negative affect, decreased motivation), but also, and possibly more

7 concerning, to 'negative effects on athletes' (e.g., behavior towards athletes, effects

8 on athletes). Collectively, the emerging empirical evidence demonstrates that athlete

9 experiences of stress can be influenced by those of the coach. Indeed, such nascent

10 findings support the comments by McCann (1997) who claimed that athletes found it

11 very easy to identify when their coaches were having stressful experiences and that

12 such episodes often led to reductions in athlete confidence. In fact, such declarations

13 provide further support for research focusing on the stressors experienced by coaches

14 and the associated responses.

Whilst it would appear that stressors experienced by coaches can negatively

16 affect the coach, and indirectly their athletes, no research has been conducted to specifically explore this hypothesis. To this end, the purpose of the present study was to provide a first systematic examination of how athletes respond to coach stress, and

19 in doing so to establish a more detailed insight into the mechanisms that operate

20 within the coach-athlete relationship. To achieve this, we had three primary foci; first,

21 we were interested in exploring how athletes identify when a coach is experiencing

22 stress. Second, we examined the varying influences of the stressors experienced by

23 coaches, on athletes. Whilst there are suggestions that athletes experience decrements

24 in confidence (e.g., Olusoga et al., 2010) little is known to how stressors influence, 25 amongst other things, broader psychological (e.g., emotions) and performance (e.g., 
1 maintained effort) constructs. Finally, with the recent focus on coach effectiveness

2 (e.g., Boardley, Kavussanu, \& Ring, 2008) we explored athlete perceptions to how

3 effective a coach is when they are perceived to be experiencing stress. Given that

4 effectiveness is often used as the yardstick by which coaches are measured (e.g.,

5 performance outcomes, development environments), we wanted to gain a better

6 understanding to the extent that athletes perceive stress experienced by a coach to

7 influence the coaches' knowledge and skills to positively affect learning and

8 performance of athletes.

\section{Method}

\section{Participants}

The purposeful sample consisted of 13 athletes (nine males and four females) representing five different sports (soccer, $n=5$; cricket, $n=3$; hockey, $n=2$; athletics, $\mathrm{n}=2$; rugby union, $\mathrm{n}=1)$. Participants ranged in age from 18 to 25 years (M 21.1, S.D. $=2.82$ ) and were either professionally contracted to play their respective sport, or classified as playing at the highest level of their sport at national level (e.g., National League). All participants fulfilled the inclusion criteria whereby they experienced regular coaching from a main coach over a sustained period of time. Further, none of the participants had experience of being a coach in a professional capacity, although many had low level experiences of coaching within their sport via 'dropping in to coaching sessions' and offering 'masterclasses'; neither of which resulted in them being labeled as a professional coach as their main source of employment. All of the participants who were initially contacted volunteered their participation for the study and signed informed consent forms prior to data collection. The research was undertaken according to the ethical guidelines of the lead author's institution.

\section{Data collection}


Preparation booklet. To facilitate the collection of data, all participants were provided with a preparation booklet (cf. Wagstaff, Fletcher, \& Hanton, 2012) prior to completing an interview. The booklet consisted of an introduction to the study, an overview of the structure and content of the interview guide, and a 'highlights and critical incidents' section. Given that the study required participants to retrospectively recall experiences, we perceived that over the course of data collection (that may have necessitated multiple interviews) the 'highlights and critical incidents' section would provide useful mixed methods and help promote prolonged participant engagement, trustworthiness in the data, and greater interaction between the data collection and the analysis phases of the study.

Interview guide. The development of the interview guide followed a review of the literature that has examined stressors within sports coaching (e.g., Frey, 2007; Olusoga et al., 2009; 2010) and athlete environments (e.g., Hanton et al., 2005; Thelwell et al., 2007), whilst also taking into consideration the extensive research and applied experiences held by members of the research team. The guide was initially piloted with two athletes from different sports to those used in the study, prior to the data collection period commencing. Following the pilot interviews, subsequent modifications to the wording of several questions took place to enhance clarity, and further probe and elaboration questions were added to enable greater detail to be captured. The final interview guide consisted of three main sections: identifying the signals of stress (e.g., "how do you know that [the coach] is experiencing stress?"), effects of coach stress on athletes (e.g., how does [the coach] being stressed affect you?"), and coach effectiveness when they are perceived to be stressed (e.g., can you provide details to whether [the coach] fulfilled their duties in an effective manner when they were experiencing stress?"). 
Data collection. Each participant was sent a copy of the preparation booklet one week prior to the scheduled interview date. All interviews were conducted faceto-face by the same researcher who was trained in qualitative techniques. A semi-

4 structured format was used, whereby the interviewees were guided through an

5 identical set of questions. Whilst this procedure resulted in a certain element of

6 structure to each of the interviews, it was important that the ordering of questions

7 varied depending on the responses from each participant, where each issue raised was explored in turn by the interviewer (Fontana \& Frey, 2003). Although the discussions

9 varied in their content (due to the participant responses), a variety of probe ("what 10 was it about [the issue] that led to...?") and elaboration ("could you elaborate on [the

11 issue] in more detail please?") questions were employed to facilitate the flow of the 12 interviews and to ensure that all issues were investigated in depth. Finally, at the end

13 of each section, participants were asked if all appropriate stressors had been

14 discussed. Interviews lasted between 40 and 74 minutes $(M=56.9$, S.D. $=10.9)$, were 15 recorded digitally, and yielded a total of 127 pages of single-spaced text having been 16 transcribed verbatim.

\section{Data Analysis}

18 To analyse the data, the first and second researchers read and re-read the

19 interview text prior to content analysing each transcript using the procedures

20 recommended by Miles and Huberman (1994). The two researchers, who were trained

21 in qualitative techniques, independently identified and coded words, phrases, quotes

22 and sayings for each of the main interview questions (Côté, Salmela, Baria, \&

23 Russell, 1993). The raw-data themes were then independently organised into groups

24 of common themes (higher order themes) resulting in the emergence of general

25 dimensions, where above this, no general meaning could be identified. Whilst the 
1 content analysis followed an inductive perspective, in the latter stages of the data

2 analysis the themes were deductively placed into post hoc categories, based on the

3 emerging themes (generated via the inductive analysis). The general dimensions were

4 chosen following the inductive phase of the analysis so to not influence the analysis.

5 Having used both inductive and deductive analyses to interpret the data into higher

6 order themes and general dimensions (Biddle, Markland, Gilbourne, Chatzisarantis, \&

7 Sparkes, 2001), the final phase of analysis was dependent upon triangular consensus

8 between the first two researchers and a third researcher who acted in the capacity of a

9 "critical friend" (Faulkner \& Biddle, 2002). The third researcher was not involved

10 with either the data collection or initial analysis of data, and they were required to

11 confirm, or otherwise, the placement of raw data themes into higher order categories.

12 In this stage of the analysis, the third researcher was required to thoroughly examine

13 all steps taken by the first two researchers in the inductive and latterly deductive

14 phase of data analysis.

15 Enhancing the trustworthiness of the analysis. Using recent guidelines

16 relating to qualitative methods (e.g., Sparkes \& Smith, 2009), checks to ensure

17 credibility, transferability, dependability and confirmability of the data were

18 implemented. First, participant debriefing, member checking, and the use of a third

19 researcher as a 'critical friend' contributed to enhancing data credibility. Second,

20 given that only 13 participants took part in the present study, it was acknowledged

21 that it was not appropriate to generalise the findings both within, and out with the

22 population examined without further data to support the findings. Third, to promote

23 dependability, a reflexive diary was used by the lead author to monitor the approach

24 employed. Finally, to promote confirmability, the data collection, treatment, and 
1 interpretation were overseen by a "critical friend", whilst the content analysis enabled

2 tracking of the data to the interview transcript.

\section{Results}

The results derived from the data analysis procedures represent the collated interview responses from all 13 participants. The raw data themes were abstracted into lower and then higher order categories prior to being organised under the following three central dimensions of research foci: signals of coach stressors; effect of coach stress on athletes; and coach effectiveness. The data are presented in Figures 1-3 and via verbatim quotations throughout the following narrative.

\section{Signals of coach stressors}

The range of signals that athletes use to detect coach stressors is illustrated in Figure 1. A total of 42 raw data themes were inductively placed into 12 lower order themes, and three higher order themes. Lower order theme signals associated with coach behaviour and appearance, primarily in the form of 'negative behaviours when talking,' and 'negative physical appearance when talking,' were the most commonly mentioned responses among the participants. The following quotation illustrates how one participant perceived their coach's negative behaviours when talking to be a signal:

[Coach] will probably use more emphasis [on key points], dumb it down a bit when [coach] is stressed as [coach] wants us to get the point quicker...it's as though we're children. But when [coach] talks there are loads more gestures, [coach] will point quite aggressively and use their arms more... at times it looks like [coach] has lost control of their arms because they're flying everywhere...they really become 
animated when they're stressed and that's when I know they are under the pump.

Further to the above, another participant commented to how they are aware that their coach is stressed because of the negative physical appearance that their coach displays when they are talking:

I can just tell it...they might be trying to talk calmly but they just seem really flustered, I mean they just frown [at the other players] and look miserable. The information is normally OK but you know that something is up, they just seem to have other things on their mind and the message almost seems lost cos they look so negative.

In addition to responses in relation to changes in behaviour and appearance, athletes reported several signals associated with changes in the coach's verbal communication. Not only were signals associated with the tone of verbal communication but the speed of delivery and reduced clarity in the messages being transmitted, and the volume of communication. The following quotation shows how one participant was able to identify that their coach was experiencing stress as a result of a negative change in the tone of the verbal communication:

I would have to say that the biggest giveaway to me would be [the coach's] tone of voice. [The coach] tends to shout a bit more... gets louder with their instructions and seems to be quite curt and at times cutting with what they say. It's pretty easy to pick up when [the coach's] tone changes cos they are always talking during team talks and training...so when [the coach] starts shouting it is a change from how they usually are. 
1 Further to the signals being related to variations in coach communication, behaviour,

2 and appearance, there were also a number of raw data themes associated with

3 extraneous factors that included the behaviour and appearance of others, and

4 environmental changes. Whilst such signals were less frequently reported, they do

5 highlight a further method by which athletes perceived their coach to be experiencing

6 stress as the following quotation illustrates:

There are just times when I arrive that I know something is up, you know, things seem different, you can just tell because people are acting differently...it tends to be quieter and more formal and everyone seems on good behaviour even to the point where the other coaches seem a bit different and on edge.

\section{Effects of coach stress on athletes}

The full range of effects of coach stress on the participants is illustrated in Figure 2. The 121 raw data themes were inductively placed into 19 lower order themes, and four higher order themes. The most commonly reported effects were those of a negative and personal nature, where the lower order theme 'unwanted cognitions', included reduced confidence, increased negativity about self-worth, and demotivation. The following quotation illustrates how one individual experienced reduced confidence in their ability as an effect of coach stress:

I just knew when [coach] was stressed and straight away I thought it was because of me. When I saw them looking over I just thought that [coach] was doubting me and it really hit me hard. I just felt like my confidence had drained and I was worthless to the point where my head had gone. It's silly really as I know now it wasn't what I thought 
but at the time the effect it had on me for what seemed ages, really got me and made me play feel like someone who didn't know what to do.

Further to the above, the following quote details how another of the participants

experienced 'unwanted cognitions' in the form of demotivation and avoidance when perceiving the coach to be experiencing stress:

I just get this thought of what's the point. I know [the coach] are struggling which means that they probably won't be on it properly and it just gets to me. My whole attitude changes for ages and I just don't see the point. It effects everything from how I feel about [the sport] to how I prepare and train and play. You can kind of track how I perform and it goes up and down and it's all about how motivated I am. I need the coach to be on it to get me thinking right but as soon as [the coach] loses it I'm gone.

A further negative and personal effect was reported in the "variable competitive performance' lower order theme. This was cited by several performers to influence how they approached performance, made them aware of the performance consequences, and influenced their preparation for competitive performances. These very points are included within the following extract: When I knew that they were going through a tough time I knew that I behaved differently. I always tried to prepare in the same way so not to get sucked in to it like the others but I did prepare differently, no two ways about it, I was pretty cautious and wanted to give the impression that I was trying extra hard rather than just doing what I needed to do...it's funny cos I probably gave more attention to how I looked when I was getting ready rather than what I needed to do. 
1 Not only did participants perceive the negative and personal effects to influence their competitive performance, they also commented how their training was negatively affected. Participants stated 'going through the motions' despite knowing training was critical, that they 'failed to prepare for training' due to a lack of coach interest, and that 'training performance was reduced' through lack of coach interest and focus.

Further to the negative effects that were of a personal valence, there were many that were negative, yet perceived as broad in nature. For example, lower order themes regarding 'sub-optimal training environments', 'inhibited competition environments', and 'ineffective communication' were commonly reported across participants. One of the interesting lower order themes was that of 'effect on the group' where one of the participants perceived the coach being stressed as effecting their club in a manner which they had not previously experienced:

As soon as they were under pressure the rumours started. OK, we are a big club and the press seem to know everything but it gets around so quick. All of a sudden there are changes talked about and new coaches mentioned if we don't get a result. Then all the staff are on edge and it really creates a bad atmosphere. You try to block it out and just do the job but when others keep talking to you about it, it's difficult.

In addition, a further quote from the lower order theme 'challenging organisational environment' revealed how one athlete's perceptions of their coach being stressed affected the group in which they performed:

We've got a few younger players in the group so they are quite nervous at times and some of us older ones will tell them not to worry and it's what happens but you see them struggling at times, especially if they haven't experienced changes before. To them, the coach liked 
them and signed them and their worry is whether another coach will like them and keep them. We try to keep the group together but they find it hard... then there are the ones who don't care, they aren't fussed whether [coach] goes or how they're feeling, that creates issues in the group as we need to pull together.

Despite the vast majority of the effects of coach stress on the athlete being reported as negative at an individual or generic level, a number of participants cited effects that were positive, and generally personal in orientation. Contrary to many of the data presented, lower order themes relating to 'facilitative cognitions', 'increased empathy', 'adopting positive behaviours', 'improved training attitude', and 'enhanced competitive environment' were reported. While reported less frequently, it appeared that participants did experience some positive effects from their coach being stressed. This is illustrated by one of the participants in the following quotation when discussing their facilitative cognitions:

For me personally, maybe cause I have had some coaching experience, I try to put myself in their position and it helps me get my head right and make me think about what I need to do. If the coach is too wrapped up in whatever, then I need to do the job myself and be clear what I'm gonna do. I can't get dragged into other stuff and I see it as an opportunity to step out of the issue.

A further two lower order themes, 'galvanised the group' and 'others negative view of the coach' were classified under the labelling of 'positive effect due to behaviour of others'. For some participants a key effect, on occasions, was for the group to come together when they realised that the coach was experiencing stress. One individual commented "seeing [the coach] up against it certainly brought us together, it was 
1 down to us. [Coach] was in the situation and we had to get it right... we had to pull

2 together to sort it". Finally, the commitment that athletes feel towards their coach

3 influenced responses, as portrayed by one individual when referring to not liking the

4 way that their coach was being talked about by others, "I knew what they were saying

5 about [the coach] and it just didn't seem right, things were difficult for him, but he

6 gave everything to us and we owed him...I couldn't have others calling him that".

\section{Coach effectiveness}

The full range of participant responses to how effective they perceive coaches

9 to be when experiencing stress is illustrated in Figure 3. The 97 raw data themes were

10 inductively placed into 23 lower order themes, and eight higher order themes. One of

11 the higher order themes was that of 'reduced competence' that included lower order

12 themes of 'poor strategy and decision making', 'indifferent technical advice', and

13 being 'unable to motivate others'. The following quotation details how one participant

14 perceived stress to reduce competence via decision making capability:

There were times when I just sat back and thought 'what on earth is going on', we've just talked about something as a squad and then a total change in direction happens that we didn't know about...some

21 Further to the perceptions of reduced competence, participants cited raw data themes

22 that were classified within the higher order theme'lack of awareness'. This was

23 developed in the form of the lower order themes 'poor management of organisational

24 demands', 'athlete well-being and general needs', 'effects on other staff', and

25 management of difficult situations'. The following outlines how one participant 
1 perceived the coach being stressed to result in a lack of awareness that effected other

2 staff:

[The coach] just didn't see what was happening, not only were they pushing everyone away from them, the other coaches were becoming quite negative as well...not only to us but to them as well. That's the last thing you want to see isn't it, the coaches not working together and in my mind it all came from [the coach] not really knowing what they were doing to others.

Another commonly cited higher order theme related to expectations and impression management that resulted from lower order themes in the areas of 'athlete expectations of coach', 'coach expectations of athlete' and, 'presentation, presence and aura of coach'. The quotation below was provided in relation to the behavioural expectations athletes had of coaches in terms of being effective:

It's not just me, but most of the others in the group too. We want [the coach] to be consistent in what they do, they talk to us about good habits and they should keep to theirs too rather than changing all the time...yeah, they have to believe in us, but all I really want is for them to be consistent so we know where we stand with them and what they want from us.

To complete the issues raised in relation to coach effectiveness, a further theme was that of a decline in performance when the coach was perceived to be experiencing stress. This was reported under the lower order themes of 'athlete performance', 'collective group performance', and 'coaches own performance'. One participant was particularly scathing in their assessment of their coach in saying, "they just didn't do their job, if they can't communicate and organise things then how can we go and 
1 perform, they have to up their game too", whilst the following reflected the thoughts

2 of another participant when commenting on their own performance: When [the coach] is going through one of those stressful times, you can tell that the performances are down, that's the biggest issue. We try to do the right thing but most of us are on edge and feeling the pressure that they are under. One mistake and that could be the end of it all and if you're talking about effectiveness, well, that's not very effective is it because it's got to us too!"

\section{Discussion}

The findings of this study extend previous studies (e.g., Frey, 2007; Olusoga et al., 2010) in reporting that athletes were clearly able to identify when their coach experiencing stress and express a variety of influences that the stress had upon them; the vast majority of them being negatively orientated. More specifically, the stress experienced by coaches can influence the relationship between themselves and their athletes. The athletes also articulated their perceptions to how effective their coach was when experiencing stress. Together, the findings provide an important progression in the coach-athlete literature that advance from an understanding of coach stress and associated coping to how their stress affects others.

Perhaps not surprisingly, athletes were predominantly able to detect coach experiences of stress via the behaviours, appearance, and style of communication adopted. The reporting of such higher order themes supports much of the work in recent coach-focused expectation and expectancy literature (e.g., Manley, Greenlees, Thelwell, Filby, \& Smith, 2008) whereby dynamic behavioural cues (e.g., tone of voice, body language and gestures) were reported as having the greatest influence on 
1 the first impressions that athletes make of coaches but were also among the most highly regarded sources of information to how athletes create expectations of coaches. Taking the above further, while hints at such signals have previously been

4 expressed (e.g., Frey, 2007), the degree to which these signals were reported in the

5 present study is somewhat overwhelming given that the coaches were operating with

6 very capable athletes where the relationship with them is essential for ongoing

7 success. In fact, it is likely the case that the closeness of the relationship enabled the

8 signals to be identified with such clarity. However, given the subsequent reported

9 influences and perceived levels of effectiveness it appears that the coaches were either

10 not aware of the signals that they were giving, of the opinion that they are able to

11 behave how they wish irrespective of the potential consequences, or, which may be

12 more likely, unable to manage their behaviours and subsequent impression

13 management to athletes when experiencing stress (cf. Olusoga et al., 2010). The

14 notion of impression management (Leary, 1992), may help to explain the findings

15 here in that the coaches may have had an inability to manage the impression that they

16 created in front of others. Such abilities point to the potential salience of emotional

17 intelligence abilities (i.e., identifying, processing and comprehending, and managing

18 emotions), which can be developed to promote individual, team, and organisational

19 effectiveness in sport (see Wagstaff, Hanton, \& Fletcher, 2013). Although data were

20 not collected to ascertain the degree to which coaches monitored and controlled how

21 they were perceived, understanding the extent to which coaches are motivated to

22 control how others see them, how they try to construct the impressions they wish

23 others to create (see Leary \& Kowalski, 1990), and the associated abilities and

24 strategies associated with the effectiveness of such transactions (see Wagstaff et al., 25 2012), may be useful in future work. 
Of course, some may argue that coaches construct specific impressions for particular situations, and that is a point for practitioners to consider. This could also mean that coaches, and athletes, can learn to plan for situations where there is a high motivation to control how others see them, which, in turn, can also help coaches become more empathetic in understanding why athletes choose to behave in the ways they do (Swider, Barrick, Harris, \& Stoverink, 2011). However, given the volume of negatively oriented effects and perceived levels of effectiveness, it is suggested that carefully developed coach education programmes are designed to enable coaches to understand what expectations athletes have of their coaches, how athletes initially see them, and how such impressions influence further transactions. Insofar as the effects of coach stress on athletes are concerned, this is something that researchers have been aware of, albeit with less detail, from athlete

13 stressor (e.g., Hanton et al., 2005) and coach studies where they have acknowledged 14 their likely effect on athletes (e.g., Olusoga et al., 2010). What is clearly reinforced 15 within the current study is that the coach is a somewhat unavoidable organisational 16 stressor for athletes. Further to this it is evident that athletes respond to organisational 17 stress (in this case their coach) via a wide range of emotions, thoughts and behaviours. 18 It is, however, important to comment that the effects on athletes were not limited to 19 personal factors and that the participants were very able to identify a number of 20 broader, generic effects. These ranged from the training and competitive environment 21 through to the organisational environment and more pertinently, the effect on the 22 group where fragmentation and job dissatisfaction were commented on. Such issues 23 have been widely commented on within the broader organisational and industrial 24 psychology literature (e.g., Weiss, 2002) and are worthy of further exploration given 25 the potential for collateral influence across an organisation (Fletcher \& Wagstaff, 
1 2009). Related to this is the notion of emotional contagion (Vijayalakshmi \&

2 Bhattacharyya, 2012) whereby the effect of the coach being stressed appeared, at

3 times, to not only influence individual behaviour but also team functioning. Given our

4 knowledge to how emotions can be infectious and that groups often respond in a

5 consistent manner, research to explore how coaches commence the process of

6 contagion, and the impact of contagion on behaviour and the overall environment is

7 warranted.

Not all of the effects cited by the participants were negative. Whilst less

9 frequently referred to, positive personal effects were evident, in the main via

10 cognitions and behaviours whereby the participants demonstrated a more goal-

11 directed approach in their response to their coach experiencing stress. It could be

12 claimed that the coach being stressed provided the athlete with an opportunity, albeit

13 unplanned, to demonstrate autonomy and competence whilst not being bound to the

14 rules and direction of the coach. This in itself is an interesting consideration for

15 coaches, athletes and practitioners in that while our knowledge of the transitions faced

16 by athletes is well known (Wylleman \& Lavellee, 2004), the processes by which

17 athletes operate to achieve independence from their coach is less understood.

18 Given the spread of effects across personal and more generic factors, the

19 findings have important implications at both a theoretical and applied level.

20 Theoretically, researchers are encouraged to continue to examine the 'stress'

21 experience and process, the contexts in which it is experienced (i.e., the coach-athlete

22 relationship) and the responses to it. In fact, the current study provides a first insight

23 into how one person's inability to manage their stress experience (i.e., the coach)

24 results in stress being experienced by someone else (i.e., the athlete) which may then

25 lead to dysfunctional, or at least less effective performance. From a practical 
1 perspective, there are a number of points when considering the effect of the coach's

2 stress on their athletes. Most prominent is the importance of making the coaches

3 aware of the effects in the first place; this may reinforce the need for them to increase

4 their awareness of rational and irrational beliefs. For athletes, given that the majority

5 of the effects were negatively oriented, it would seem plausible to work with them to

6 modify the appraisals that they have in response to when their coach is stressed. This

7 could also be extended to include rational-emotive behaviour therapy approaches that

8 have recently been advocated in the applied sport psychology literature (e.g., Turner

$9 \quad \&$ Barker, 2014) where athletes develop their capability to reappraise stressors (i.e.,

10 the coach) and focus on aspects of the environment and their performance that they

11 are able to control. Such an approach is not limited to being reactive in nature and

12 would provide coaches, and athletes, with an opportunity to be proactive in

13 considering the varying effects that they will be required to cope with, and manage.

14 Despite previous references to signals and effects of coach stress, the present

15 study is the first to explore the athlete perceptions of coach effectiveness when the

16 coach is experiencing stress. The findings provide a number of salient observations

17 regarding the well-being of the coach-athlete relationship. Importantly, athletes

18 perceived coaches to be performers in their own right, as evidenced by them

19 commenting that coach performance, in addition to their own, typically declines when

20 they are experiencing stress (Gould et al., 2002). In support, it was also apparent that

21 coaches were perceived to be less effective when experiencing stress, to demonstrate

22 reduced competence, and have increased variability in their expectations of athletes,

23 which in turn is reciprocated by athletes having changeable expectations of the

24 coaches. Put together, the reduced effectiveness and competence is likely to have

25 reputational consequences for coaches given the well documented behavioural 
1 responses to indifferent or poor reputations (e.g., Manley, Greenlees, Smith, Batten, \&

2 Birch, 2014). Coaches and practitioners are advised to be aware of such issues.

As with any investigation of this kind, this study is not without its limitations,

4 with arguably the greatest weakness being the retrospective nature of the interview

5 design. Due to the data collection being after when the events had occurred, it remains

6 difficult to precisely recall events and eliminate any memory bias. For example, the

7 athletes who experienced slumps in their performance levels may have recalled less

8 favourable responses (e.g., greater intensity of signals, more profound effects)

9 compared to those who maintained, or had minimal performance disruption (Dugdale,

10 Eklund, \& Gordon, 2002). Furthermore, the researchers did not protect against any

11 potential coach-athlete relationship issues given that the inclusion criteria for

12 participation only required the athletes to be regularly coached by the same

13 individual. No data regarding the length of the association, or any relationship issues

14 at the time of the interview were collected, and going forward, given some of the

15 reported outcomes it could be that such information may prove fruitful to see whether

16 there are any extraneous factors that might mediate the responses from athletes.

This discussion illustrates that the coach-athlete relationship is intricate and

18 that athletes can detect and be effected by the stress experienced by their coach. As

19 such, a priority for future researchers that keeps within the culture of 'reflective

20 practitioners' in which coaches operate (cf. Cropley, Hanton, Miles, \& Niven, 2010)

21 is establishing the degree to which coaches are aware of the signals that they transmit

22 when stressed, how they perceive athletes to be effected when they are stressed, and

23 how effective they perceive themselves to be when experiencing stress. Only when

24 such information is available will the much needed coach-focused interventions (i.e.,

25 impression management, stress management) have the sufficient research 
1 underpinning for development, research, and subsequent implementation by

2 practitioners. On this point, given that it was not a focus of the current study, it is also

3 necessary to examine the degree to which coaches actually express their felt responses

4 to stressors experienced and also the extent to which there are differences in coaches'

5 and athletes' actual ability to detect signals in themselves and others. The suggestion

6 that coaches should mask their emotions reinforces the notion of emotional labor (see,

7 for a recent review, Grandey, Diefendorff, \& Rupp, 2013; see also Tamminen, \&

8 Crocker, 2013) whereby individuals often display organisationally desired emotions

9 rather than those that they are experiencing. It may well, therefore, be that the

10 displaying of 'desired' emotions is of detriment to the coach in terms of their general

11 well-being and general effectiveness.

In conclusion, athletes identified signals of stress within their coaches, to how

13 they are affected by the coach experiencing stress, and to how effective they perceive

14 coaches to be when the coach is experiencing stress. The theoretical and practical

15 implications of this research also provide a firm rationale for the design of coach

16 education courses to enhance coach performance, and stimulate further research on

17 the coach-athlete relationship.

19 Bennett, P., Lowe, R., Matthews, V., Dourali, M., \& Tattersall, A. (2001). Stress in nurses: Coping managerial support and work demand. Stress and Health, 17, $55-63$.

22 Biddle, S.J.H., Markland, D., Gilbourne, D., Chatzisarantis, N.L.D., \& Sparkes, A.C. (2001). Research methods in sport and exercise psychology: Quantitative and qualitative issues. Journal of Sports Sciences, 19, 777-809. 
1 Boardley, I.D., Kavussanu, M., \& Ring, C. (2008). Athletes' perceptions of coaching effectiveness and athlete-related outcomes in rugby union: An investigation based on the coaching efficacy model. The Sport Psychologist, 22, 269-287.

Côté, J., Salmela, J.H., Baria, A., \& Russell, S.J. (1993). Organizing and interpreting unstructured qualitative data. The Sport Psychologist, 7, 127-137.

Cropley, B., Hanton, S., Miles, A., \& Niven, A. (2010). The value of reflective practice in professional development: An applied sport psychology review. Sports Science Review, 19, 179-209.

Dugdale, J.R., Eklund, R.C., \& Gordon, S. (2002). Expected and unexpected stressors in major international competition: Appraisal, coping, and performance. The Sport Psychologist, 16, 20-33.

Faulkner, G., \& Biddle, S.J.H. (2002). Mental health nursing and the promotion of physical activity. Journal of Psychiatric and Mental Health Nursing, 9, 659665.

Fletcher, D., Hanton, S., \& Mellalieu, S. D. (2006). An organizational stress review: Conceptual and theoretical issues in competitive sport. In S. Hanton \& S. D. Mellalieu (Eds.), Literature reviews in sport psychology (pp. 321-373). Hauppauge, NY: Nova Science.

Fletcher, D., Hanton, S., \& Wagstaff, C.R.D. (2012). Performers' responses to stressors encountered in sport organisations. Journal of Sports Sciences, 30 349-358.

Fletcher, D., Rumbold, J.L., Tester, R., \& Coombes, M.S. (2011). Sport psychologists' experiences of organizational stressors. The Sport Psychologist, $25,363-381$. 
1 Fletcher, D., \& Scott, M. (2010). Psychological stress in sports coaches: A review of concepts, research, and practice. Journal of Sports Sciences, 28, 127-137.

Fletcher, D., \& Wagstaff, C.R.D. (2009). Organizational psychology in elite sport: Its emergence, application and future. Psychology of Sport and Exercise, 10, 427434.

Fontana, A., \& Frey, J.H. (2003). The interview: From structured questions to negotiated text. In N.K. Denzin \& Y.S. Lincoln (Eds.), Collecting and interpreting qualitative materials (pp.61-106). Thousand Oaks: Sage.

Frey, M. (2007). College coaches' experiences with stress - "Problem solvers have problems, too". The Sport Psychologist, 21, 38-57.

Gearity, B.T., \& Murray, M.A. (2011). Athletes' experiences of the psychological effects of poor coaching. Psychology of Sport and Exercise, 12, 213-221.

Gould, D., Greenleaf, C., Guinan, D., \& Chung, Y. (2002). A survey of U.S. Olympic coaches: Variables perceived to have influenced athlete performances and coach effectiveness. The Sport Psychologist, 16, 229-250.

Gould, D., Greenleaf, C., Guinan, D., Dieffenbach, K., \& McCann, S. (2001). Pursuing performance excellence: Lessons learned from Olympic athletes and coaches. Journal of Excellence, 4, 21-43.

Grandey, A., Diefendorff, J., \& Rupp, D.E. (Eds.). (2013). Emotional labor in the 21st century: Diverse perspectives on emotion regulation at work. London: Routledge.

Hanton, S., Fletcher, D., \& Coughlan, G. (2005). Stress in elite sport performers: A comparative study of competitive and organizational stressors. Journal of Sports Sciences, 23, 1129-1141. 
1 Harwood, C. \& Knight, C. (2009). Understanding parental stressors: An investigation of British tennis players. Journal of Sports Sciences, 27, 339-351.

Holt, N.L., \& Hogg, J.M. (2002). Perceptions of stress and coping during preparations for the 1999 women's soccer World Cup finals. The Sport Psychologist, 16, $251-271$

Kerr, R., McHugh, M., \& McCrory, M. (2009). HSE Management Standards and stress related work outcome. Occupational Medicine, 59, 574-579.

Kinman, G., \& Jones, F. (2008). Effort-reward imbalance, over-commitment and work-life conflict: Testing an expanded model. Journal of Managerial Psychology, 23, 236-251.

Knight, C.J., Reade, I.L., Selzler, A.M., \& Rodgers, W.M. (2013). Personal and situational factors influencing coaches' perceptions of stress. Journal of Sports Sciences, 31, 1054-1063.

Kristiansen, E., \& Roberts, G.C. (2010). Young elite athletes and social support: Coping with competitive and organizational stress in "Olympic" competition. Scandinavian Journal of Medicine and Science in Sports, 20, 686-695.

Leary, M.R. (1992). Self-presentational processes in exercise and sport. Journal of Sport and Exercise Psychology, 14, 339-351.

Leary, M.R., \& Kowalski, R.M. (1990). Impression management: A literature review and two-component model. Psychological Bulletin, 107, 34-47.

Manley, A.J., Greenlees, I.A., Smith, M.J., Batten, J., \& Birch, P.D.J. (2014). The influence of coach reputation on the behavioural responses of male soccer players. Scandinavian Journal of Medicine and Science in Sports, 24, 111120.

Manley, A.J., Greenlees, I.A., Thelwell, R.C., Filby, W.C.D., \& Smith, M.J. (2008). 
Athletes' perceptions of the sources of information used when forming initial impressions and expectancies of a coach. The Sport Psychologist, 22, 73-89.

McCann, S. (1997). Overcoaching and undercoaching: What pressure can do to coaches. Olympic Coach, 7, 12.

Miles, M.B., \& Huberman, A.M. (1994). Qualitative data analysis: An expanded sourcebook ( $2^{\text {nd }}$ ed.). Thousand Oaks, CA: Sage.

Noblet, A.J., \& Gifford, S.M. (2002). The sources of stress experienced by professional Australian footballers. Journal of Applied Sport Psychology, 14, $1-13$.

Olusoga, P., Butt, J., Hays, K., \& Maynard, I. (2009). Stress in elite sports coaching: Identifying stressors. Journal of Applied Sport Psychology, 21, 442-459.

Olusoga, P., Butt, J., Maynard, I., \& Hays, K. (2010). Stress and coping: A study of world class coaches. Journal of Applied Sport Psychology, 22, 274-293.

Poczwardowski, A., Barott, J.E., \& Jowett, S. (2006). Diversifying approaches to research on athlete-coach relationships. Psychology of Sport and Exercise, 7, 125-142.

Sparkes, A.C., \& Smith, B. (2009). Judging the quality of qualitative inquiry: Criteriology and relativism in action. Psychology of Sport and Exercise, 10, 491-497.

Swider, B.W., Barrick, M.R., Harris, T.B., \& Stoverink, A.C. (2011). Managing and creating an image in the interview: The role of interviewee initial impressions. Journal of Applied Psychology, 96, 1275-1288.

Tamminen, K. A., \& Crocker, P. R. (2013). “I control my own emotions for the sake of the team": Emotional self-regulation and interpersonal emotion regulation 
among female high-performance curlers. Psychology of Sport and Exercise, 14, 737-747.

Thelwell, R.C., Weston, N.J.V., \& Greenlees, I.A. (2007). Batting on a sticky wicket: Identifying sources of stress and associated coping strategies for professional cricket batsmen. Psychology of Sport and Exercise, 8, 219-232.

Thelwell, R.C., Weston, N.J.V., Greenlees, I.A., \& Hutchings, N.V. (2008). Stressors in elite sport: A coach perspective. Journal of Sports Sciences, 26, 905-918.

Turner, M.J., \& Barker, J.B. (2014). Using rational emotive behaviour therapy with athletes. The Sport Psychologist, 28, 75-90.

Vijayalakshmi, V., \& Bhattacharyya, S. (2012). Emotional contagion and its relevance to individual behaviour and organizational processes: A position paper. Journal of Business and Psychology, 27, 363-374.

Wagstaff, C. R. D., Fletcher, D., \& Hanton, S. (2012). Exploring emotion abilities and regulation strategies in sport organizations. Sport, Exercise, and Performance Psychology, 1, 268-282.

Wagstaff, C. R., Hanton, S., \& Fletcher, D. (2013). Developing emotion abilities and regulation strategies in a sport organization: An action research intervention. Psychology of Sport and Exercise, 14(4), 476-487.

Weiss, H.M. (2002). Deconstructing job satisfaction: Separating evaluations, beliefs and affective experiences. Human Resource Management Review, 12, 1-22.

Wylleman, P.\& Lavellee, D. (2004). A development perspective on transitions faced by athletes. In M. Weiss (Ed.), Developmental sport and exercise psychology: A lifespan perspective (pp. 507-527). Fitness Information Technology, Morgantown, WV. 
Figure Captions

2 Figure 1. Signals of coach stressors (numbers in parentheses illustrate the number of

3 participants citing the source when $>1$ )

4 Figure 2. Effects of coach stress on athletes (numbers in parentheses illustrate the

5 number of participants citing the source when $>1$ )

6 Figure 3. Coach effectiveness (numbers in parentheses illustrate the number of

7 participants citing the source when $>1$ )

8 
Figure 1.

\begin{tabular}{|c|c|c|c|}
\hline $\begin{array}{l}5 \\
3\end{array}$ & $\begin{array}{l}\text { Reduced communication with players } \\
\text { Reduced communication between coaches }\end{array}$ & Change in volume of verbal communication & \multirow{5}{*}{$\begin{array}{l}\text { Changes in coach verbal } \\
\text { communication }\end{array}$} \\
\hline $\begin{array}{l}8 \\
7 \\
7 \\
5 \\
5 \\
5 \\
5 \\
4 \\
2 \\
2 \\
2\end{array}$ & $\begin{array}{l}\text { Tendency to shout orders at players } \\
\text { Negative delivery of instructions } \\
\text { Regular raising of voice } \\
\text { Increased use of profanity } \\
\text { Blunt instructions } \\
\text { Aggressive delivery of instructions } \\
\text { Adopts a 'blame others' approach } \\
\text { Becomes more serious when talking } \\
\text { Lacks willingness to interact }\end{array}$ & $\begin{array}{l}\text { Negative change in tone of verbal } \\
\text { communication }\end{array}$ & \\
\hline 3 & Increased speed to delivery of information & Speed of delivery of verbal communication & \\
\hline $\begin{array}{l}7 \\
3 \\
2 \\
\end{array}$ & $\begin{array}{l}\text { Confused messages } \\
\text { Too much information provided } \\
\text { Inability to stay in the 'here and now' }\end{array}$ & Reduced clarity of verbal communication & \\
\hline 2 & Shorter focused information & Enhanced clarity of verbal communication & \\
\hline $\begin{array}{l}10 \\
10 \\
9 \\
5 \\
4 \\
3\end{array}$ & $\begin{array}{l}\text { Becomes more animated } \\
\text { Appears agitated and fidgety } \\
\text { Increased use of hand/arm gestures } \\
\text { Increased pacing } \\
\text { Crosses arms when talking } \\
\text { Lack of eye contact with players }\end{array}$ & Negative behaviours when talking & \multirow{5}{*}{$\begin{array}{l}\text { Changes in coach behaviour and } \\
\text { appearance }\end{array}$} \\
\hline $\begin{array}{l}11 \\
3 \\
4\end{array}$ & $\begin{array}{l}\text { Appears flustered } \\
\text { Frowning at players } \\
\text { Looks tired }\end{array}$ & Negative physical appearance when talking & \\
\hline $\begin{array}{l}4 \\
2 \\
2\end{array}$ & $\begin{array}{l}\text { Becomes very quiet within sessions } \\
\text { Becomes too agreeable } \\
\text { Lack of availability }\end{array}$ & Becomes more reserved & \\
\hline $\begin{array}{l}6 \\
2\end{array}$ & $\begin{array}{l}\text { Instructions delivered by other coaches } \\
\text { Players are left alone }\end{array}$ & Passing of responsibilities & \\
\hline $\begin{array}{l}4 \\
2 \\
2\end{array}$ & $\begin{array}{l}\text { Becomes overly fussy } \\
\text { Seems to be doing 'too many' jobs } \\
\text { Drinks more tea/coffee }\end{array}$ & Obvious general behaviours & \\
\hline $\begin{array}{l}3 \\
2\end{array}$ & $\begin{array}{l}\text { Other coaches appear reserved when around coach } \\
\text { Other coaches mirror head coach behaviour }\end{array}$ & Behaviour and appearance of others & \multirow[b]{2}{*}{ Non-coach related signals } \\
\hline $\begin{array}{l}4 \\
3 \\
2 \\
1 \\
1\end{array}$ & $\begin{array}{l}\text { Atmosphere feels different } \\
\text { Sense of uncertainty } \\
\text { Lack of organisation } \\
\text { Things feel rushed } \\
\text { Changing room conversations }\end{array}$ & Environmental changes & \\
\hline
\end{tabular}


Figure 2

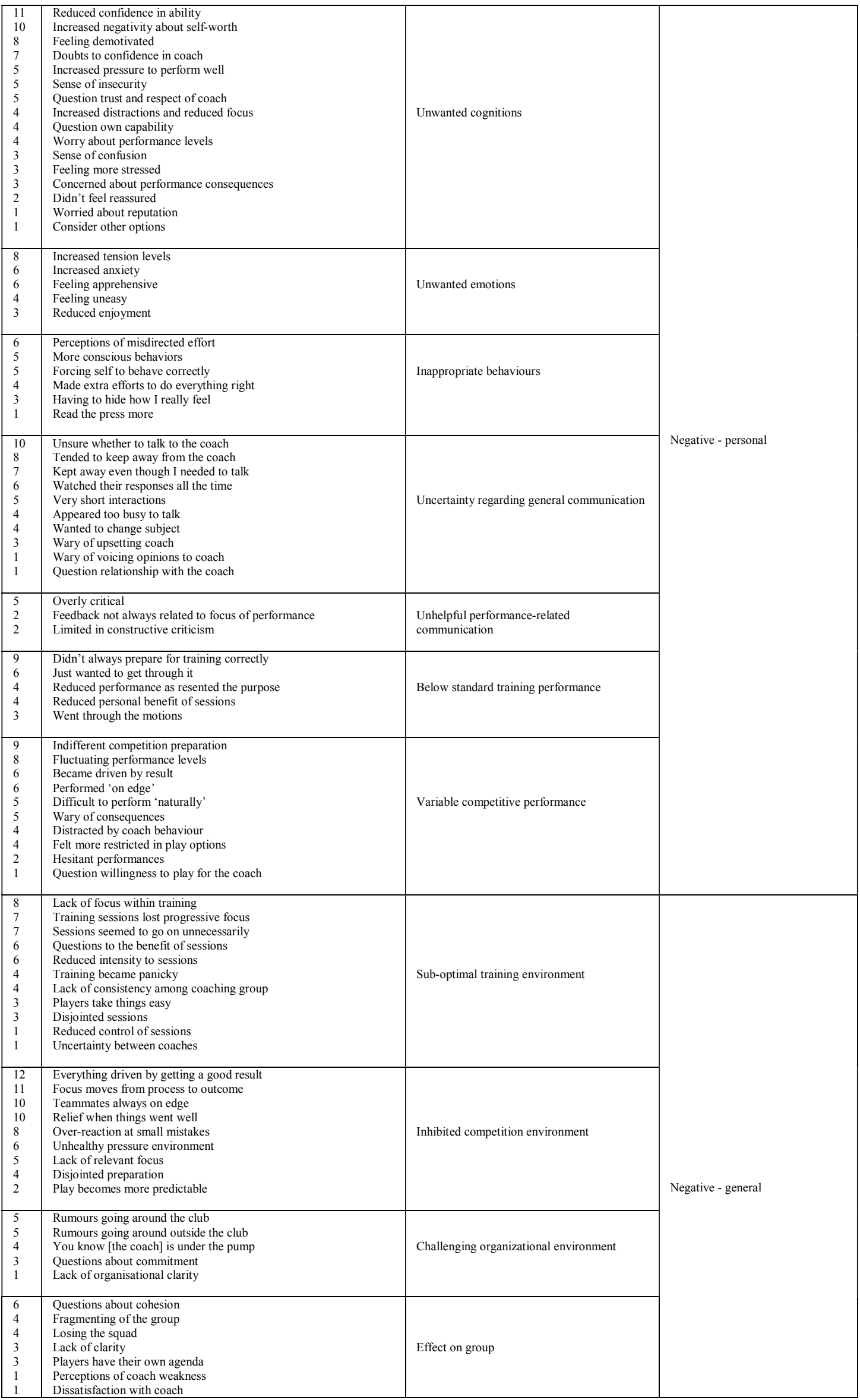




\begin{tabular}{|c|c|c|c|}
\hline & & \multirow{6}{*}{ Ineffective communication } & \\
\hline $\begin{array}{l}10 \\
9\end{array}$ & $\begin{array}{l}\text { Change in communication style } \\
\text { Passing of responsibility to others }\end{array}$ & & \\
\hline 7 & More 'protectionist' and needing to justify & & \\
\hline 5 & Reluctance to communicate & & \\
\hline 5 & Players feel coach is unapproachable & & \\
\hline 3 & Less advice provided & & \\
\hline 4 & Realisation to work for the coach & \multirow{9}{*}{ Facilitative cognitions } & \multirow{21}{*}{ Positive - personal } \\
\hline 4 & Refocus on key role & & \\
\hline 3 & Realign focus & & \\
\hline 2 & Attitude to help the coach & & \\
\hline 2 & Wanting to prove resilience & & \\
\hline 2 & Motivated to correct the situation & & \\
\hline 1 & Review performance process & & \\
\hline 1 & Forget the outcome & & \\
\hline 1 & Wanting to perform for coach & & \\
\hline 4 & Putting self in their position & Increased empathy & \\
\hline 2 & Knowing how we would feel & & \\
\hline 5 & Increased task effort & \multirow{6}{*}{ Adopting positive behaviours } & \\
\hline 5 & Increased work rate & & \\
\hline 4 & Play for the coach & & \\
\hline 3 & Assume responsibility & & \\
\hline 3 & Hide how I really feel & & \\
\hline 2 & Become more vocal & & \\
\hline 3 & Taking a lead in training & \multirow[t]{2}{*}{ Improved training attitude } & \\
\hline 1 & Focus on training achievements & & \\
\hline 2 & Greater focus on preparation & \multirow[t]{2}{*}{ Enhanced competitive environment } & \\
\hline 1 & Disregard outcome focus & & \\
\hline 3 & Brought players together & \multirow{4}{*}{ Galvanised the group } & \multirow{6}{*}{$\begin{array}{l}\text { Positive effect due to behaviour of } \\
\text { others }\end{array}$} \\
\hline 2 & Developed an all-in mentality & & \\
\hline 1 & Worked better for each other & & \\
\hline 1 & Wanting to prove others wrong & & \\
\hline 1 & Opposition thought it would be easy & \multirow[t]{2}{*}{ Others' negative view of coach } & \\
\hline 1 & Others talked bad of the coach & & \\
\hline
\end{tabular}


Figure 3

\begin{tabular}{|c|c|c|c|}
\hline $\begin{array}{l}7 \\
6 \\
5 \\
4 \\
4 \\
2\end{array}$ & $\begin{array}{l}\text { Made strange decisions } \\
\text { Wasn't decisive when could have been } \\
\text { Odd selection } \\
\text { Seemed to take the safe options too much } \\
\text { Lots of indecision } \\
\text { Uncertainty in decisions }\end{array}$ & Poor strategy and decision making & \multirow{3}{*}{ Reduced competence } \\
\hline $\begin{array}{l}6 \\
4 \\
2\end{array}$ & $\begin{array}{l}\text { Confusing messages } \\
\text { Didn't seem sure about advice } \\
\text { Inconsistency in what had been said before }\end{array}$ & Indifferent technical advice & \\
\hline $\begin{array}{l}6 \\
2 \\
2\end{array}$ & $\begin{array}{l}\text { Seemed preoccupied } \\
\text { Lacked the drive and desire } \\
\text { Didn't get the players playing for them }\end{array}$ & Unable to motivate others & \\
\hline $\begin{array}{l}7 \\
8 \\
5\end{array}$ & $\begin{array}{l}\text { Got told what to do more of the time } \\
\text { Lack of input from us } \\
\text { Much more instruction }\end{array}$ & Increased autocratic behaviours & \multirow{4}{*}{ Variable behaviours } \\
\hline $\begin{array}{l}3 \\
3 \\
1\end{array}$ & $\begin{array}{l}\text { Let us make all the decisions } \\
\text { Didn't want ownership } \\
\text { More team led discussions }\end{array}$ & Increased democratic behaviours & \\
\hline $\begin{array}{l}5 \\
4 \\
2\end{array}$ & $\begin{array}{l}\text { More critical feedback } \\
\text { Lack of positive information } \\
\text { No praise given }\end{array}$ & Reduced positive feedback & \\
\hline $\begin{array}{l}6 \\
5 \\
5 \\
3\end{array}$ & $\begin{array}{l}\text { More obvious behaviours during performance } \\
\text { Pacing on the side } \\
\text { Increased use of gestures } \\
\text { Shaking of head and turning away }\end{array}$ & Unhelpful behaviours & \\
\hline $\begin{array}{l}5 \\
5 \\
4 \\
3 \\
1 \\
1\end{array}$ & $\begin{array}{l}\text { Lack of organisation at training } \\
\text { Indifferent timekeeping } \\
\text { Appears to be very rushed } \\
\text { Shares too much information } \\
\text { Too concerned with the bigger organisational picture } \\
\text { Lack of trust in others }\end{array}$ & Poor management of organisational demands & \multirow{4}{*}{ Lack of awareness } \\
\hline $\begin{array}{l}6 \\
6 \\
5 \\
5 \\
5 \\
4 \\
2 \\
2 \\
1 \\
1\end{array}$ & $\begin{array}{l}\text { Unaware to athlete needs pre-performance } \\
\text { Forgets about athlete needs } \\
\text { Doesn't hide their feelings } \\
\text { Reduced communication } \\
\text { Reduced empathy and understanding } \\
\text { Barrier to listening to athletes } \\
\text { Unaware of effects on athletes } \\
\text { Importance of giving athletes confidence } \\
\text { Reduced enjoyment }\end{array}$ & Athlete well-being and general needs & \\
\hline $\begin{array}{l}5 \\
4 \\
4 \\
3 \\
2\end{array}$ & $\begin{array}{l}\text { Fractured coaching/support team } \\
\text { Become isolated } \\
\text { Other coaches appear negative } \\
\text { Other coaches appear unsure } \\
\text { Others stay out of the way }\end{array}$ & Effects on other staff & \\
\hline $\begin{array}{l}4 \\
3 \\
3 \\
2 \\
2\end{array}$ & $\begin{array}{l}\text { Doesn't think through consequences } \\
\text { Heart rules head } \\
\text { Too emotional } \\
\text { Needs to think through actions } \\
\text { Not always a rational response }\end{array}$ & Management of difficult situations & \\
\hline $\begin{array}{l}5 \\
5 \\
3\end{array}$ & $\begin{array}{l}\text { Wanting consistency in approaches } \\
\text { To have belief in athletes } \\
\text { To give athletes the best mind-set possible to perform }\end{array}$ & Athlete expectations of coach & \multirow{3}{*}{$\begin{array}{l}\text { Poor expectation and impression } \\
\text { management }\end{array}$} \\
\hline $\begin{array}{l}5 \\
4 \\
1\end{array}$ & $\begin{array}{l}\text { Increased expectations } \\
\text { Unrealistic expectations } \\
\text { Pick things up quicker than usual }\end{array}$ & Coach expectations of athlete & \\
\hline $\begin{array}{l}6 \\
4 \\
3 \\
3 \\
2 \\
2\end{array}$ & $\begin{array}{l}\text { Lacking in confidence } \\
\text { No belief in what they are doing } \\
\text { Reserved behaviour } \\
\text { No presence } \\
\text { Look uncomfortable }\end{array}$ & Presentation, presence and aura of coach & \\
\hline $\begin{array}{l}6 \\
4 \\
4 \\
3 \\
2\end{array}$ & $\begin{array}{l}\text { Variable performance } \\
\text { Didn't always play with confidence } \\
\text { Hard to focus } \\
\text { Played on edge } \\
\text { Played without belief of coach }\end{array}$ & Athlete performance & \multirow{3}{*}{ Decline in performance } \\
\hline $\begin{array}{l}3 \\
2 \\
1 \\
1\end{array}$ & $\begin{array}{l}\text { Never really got going } \\
\text { Passing of responsibility } \\
\text { Hard for someone to take control } \\
\text { Players looked for the leader more }\end{array}$ & Collective group performance & \\
\hline $\begin{array}{l}6 \\
5 \\
4 \\
4 \\
4 \\
3 \\
2 \\
1\end{array}$ & $\begin{array}{l}\text { Poorer communication } \\
\text { Preparation seemed inconsistent } \\
\text { Performance review was very critical } \\
\text { Lack of training structure } \\
\text { Too focused on result } \\
\text { Too intense } \\
\text { Too much pressure on themselves } \\
\text { Management of officials }\end{array}$ & Coaches own performance & \\
\hline
\end{tabular}




\begin{tabular}{|c|c|c|c|}
\hline $\begin{array}{l}2 \\
2 \\
1\end{array}$ & $\begin{array}{l}\text { Let us have more freedom } \\
\text { Enhanced sense of responsibility } \\
\text { 'Get out of it what you want' mind-set }\end{array}$ & Input to training & \multirow[t]{2}{*}{ Productive preparation } \\
\hline $\begin{array}{l}2 \\
2\end{array}$ & $\begin{array}{l}\text { Sharper sessions } \\
\text { You know you have to be 'on it' }\end{array}$ & Session content & \\
\hline $\begin{array}{l}4 \\
3 \\
2\end{array}$ & $\begin{array}{l}\text { Reduced amount of information } \\
\text { Focused information } \\
\text { Playing for your place }\end{array}$ & Information & \multirow{2}{*}{ Focused performances } \\
\hline $\begin{array}{l}4 \\
3 \\
1\end{array}$ & $\begin{array}{l}\text { Expectation of increased effort } \\
\text { Need to do the right things at all times } \\
\text { Have 'spot on' standards }\end{array}$ & Behaviours & \\
\hline $\begin{array}{l}2 \\
2 \\
1\end{array}$ & $\begin{array}{l}\text { Need to become resilient } \\
\text { Need to be determined } \\
\text { Need to develop toughness }\end{array}$ & Developing a harder mind-set & \multirow{2}{*}{ Develop mind-set and awareness } \\
\hline $\begin{array}{l}3 \\
3 \\
2 \\
1\end{array}$ & $\begin{array}{l}\text { Understand coach pressures more } \\
\text { Be aware that it isn't always easy for coaches } \\
\text { Learn to be rationale when receiving feedback } \\
\text { No 'ideal world' }\end{array}$ & Enhance understanding of coach role & \\
\hline
\end{tabular}

